\title{
Function of Weather Derivatives in Risk Management
}

\author{
Xinyuan Zhang \\ School of Economics \\ Henan University \\ Kaifeng, China
}

\begin{abstract}
Weather change has very close relation with economy and life of human-beings. China has always been the big agricultural country. We are used to the model of "living depends on climate" so that we are quite sensitive to the change of weather. Besides agriculture, the operating scale and gain of industries of energy, construction, and tourism are also facing to risks of weather change. Targeting for the situation that the weather risk factor has more and more serious affect on the economy and life of human beings, as a kind of most effective new model risk management instrument which is specially used for preventing common weather risk, the weather derivatives is not only an innovation of financial derivative instrument, but also the product of highly optimization of capital market, having very bright development potential in the future.
\end{abstract}

Keywords-Weather Derivative; Risk Management; Agriculture

\section{INTRODUCTION}

Due to the affect of human's economic and social living activities, our planet is suffering obvious change, for which, the climate warming is the key characteristic. The changed climate results in glacier melting and rising of sea level, bad extreme weather, reduction of grain output, and species extinction. The changing climate also brings huge losses to all industries of our nation, such as natural disasters of hail, draught, and flood directly affecting the output of grain, energy industry, transport industry, and construction industry. In 2013, China suffered multiple times of severe disasters, including Lushan strong earthquake of Sichuan, Minxian County and Zhangxian County earthquakes of Gansu, serious flood in northeast basin, hot temperature and draught in large area of southern part of China, and typhoon, storm, and flood of coastal region of southern part of China. As the instrument of preventing weather risk, the development of weather derivatives can help price finding in market and can perform hedging for enterprises and farmers encountering risks. If this can be developed and applied in market as soon as possible, it is for sure to effectively reduce the losses of enterprise and farmer brought by weather risk.

\section{WEATHER RISK}

Weather risk refers to the phenomenon that people's life, production, and operation, or certain commodity's production cost and market demand fluctuate due to nondisaster weather events as rainfall volume, temperature, humidity, and snowfall volume, which further result in uncertain changes to cash flow and gain of economic entity. The weather changes have very important affect on the economic activities of industries of agriculture, transportation, construction, and tourism. With the social and economic development, the demand on weather risk management of these industries would become more and more urgent.

\section{WEATHER DERIVATIVES}

Market of weather derivatives started from North America in 1997. In order to avoid bad affect of nonanticipated weather change, Enron and Koch Energy signed the first batch of weather derivatives contract in the world, which indicated the formal start-up of weather derivatives market. Since its foundation, the development speed of weather derivatives market is amazing. And the trading scale, types, and participants increase every year. Especially, it is prosperously developed in European and American securities market. Investors can not only perform hedging by purchasing various kinds of weather risk products from capital market, but also acquire profits by various kinds of trading and changes of weather. The weather factor and payment variable in the weather derivatives contract are flexible and easy for operation. Enterprises may disperse the possible weather risks by purchasing proper weather derivatives, thus to realize the purpose of risk transfer.

The weather derivatives market is one of financial markets having most potential. As a kind of financial derivatives instrument innovation, it is the output of optimized capital market and highly developed market economy. With the further development of market, the weather derivatives market attracts more and more attention from European and Asia-Pacific Region countries, such as Grate Britain, France, Germany, Switzerland, and Japan, etc. It is becoming globalization day by day. And with the further deepening of economic globalization and financial integration tendency, the prospect of the weather derivatives would surely attract people's attention.

\section{CurRent Market Status of Domestic Weather DERIVATIVES}

China has vast territory, complicated and diversified weather changes. It is one of the countries suffering most severe affect of weather risk in the world. According to the data of Ministry of Civil Affairs, direct economic loss brought by weather disaster to China in 2013 reached 202 
billion. The problem that China is attacked by weather risk has attracted wide attention of the society. Especially, in 2014 and 2014, the smog weather appeared and could hardly be defeated which makes people feel anxious about that. Smog weather can not only harm people's body health, but also directly affect the industries of transportation and energy, etc.

Facing to the weather risk, the preventive measures that we are now taking include risk retention, government relief, agricultural insurance, and agriculture futures. We have established four futures exchanges, among which, Dalian Commodity Exchange, Zhengzhou Commodity Exchange, and Shanghai Futures Exchange are mainly engaging in transactions of commodity futures, such as soybean, white sugar, and gold, while the China Financial Futures Exchange is mainly engaged in transactions of financial derivatives as stock index futures. Up to now, domestic weather derivatives market is still a gap.

China has always been a big agriculture country since ancient times. However, the predicament of Chinese farmers "living depend on weather" sufficiently indicates that the Chinese agriculture is highly sensitive to weather change. Bad weather change would result in losses to agriculture. Government subsidy and social relief though could solve the matter in extreme urgency, for long, this would both increase state financial burden and affect development of other industries. Besides agriculture, industries of energy, construction, and tourism are also sensitive to weather change. Their gains also face to the weather risks. Therefore, gradually establishing and optimizing weather risk management system, developing and promoting the market of weather derivatives would be preferential for the durable and stable development of socialist market economy.

Dalian Commodity Exchange had started preliminary study on weather derivatives in 2002. It cooperates with National Meteorological Center and has submitted the application for being listed of contract based on temperature index futures to CSRC for examination and approval. It is hoped to launch weather derivatives as temperature index futures to the market when opportunity is mature.

In a word, the weather derivatives market has huge development potential and good prospect in China. And meanwhile, we are still facing many problems that are urgent for being settled during the continuous exploration and study process.

\section{PRACTICAL SIGNIFICANCE FOR US TO LAUNCH WEATHER DERIVATIVES}

\section{A. Provide Enterprises with A Kind of Risk Dispersing Channel}

Weather derivatives endows enterprises a new kind of risk dispersing channel, which is also one of the important financial instruments for enterprises to realize weather risk management. After bringing in weather derivatives, the function of financial instrument to adjust natural loss can be exerted sufficiently, thus to take the advantage of financial market to realize risk transfer. For market participants highly sensitive to weather change, such as agriculture, energy, construction, transportation, traffic, tourism, and insurance companies, they can take advantage of capital market to realize weather risk dispersing and transfer by participating in weather derivatives trading, thus to further realize purpose of hedging. The trading transaction for weather derivatives exerts importance weather risk management function to these market participants.

\section{B. Enrich Investment Types and Provide New Investment Channel}

Besides hedging, another type of market participant is speculator, who is in the hope to seek for small risk, high gain, and powerful fluidity investment types from financial market by a series of capital operating to construct optimized assets combination, thus to further disperse risks and increase gains. Financial derivatives types now on domestic financial market are only a few. And the development of financial derivatives instrument is comparatively slow. Facing to the diversified demands of investors, it is necessary for us to refer to foreign experience, take advantage of advanced theoretical instruments and technologies to design new types of products satisfying demands of different investors. The launching of weather derivatives enriches the investment types of Chinese capital market, and plays important role in making capital market more prosperous and satisfying diversified investment demands.

\section{Realize Financial Innovation and Foster Financial Talents}

At the beginning of 1990s, as a newly emerged subject, financial engineering was firstly developed in European and American developed countries. It mainly studies the pricing and applying of financial derivatives instrument. The financial engineering takes mathematics model as the basis and designs financial products to satisfy different investors. The financial derivative is one of its big innovations. The continuous development of financial derivatives market depends on excellent learners and financial talents having innovative spirits. We shall pay more attention to the fostering of talents in order to obtain high quality interdisciplinary talents mastering both consolidated financial mathematics theoretical knowledge and information technology. The launching of weather derivatives provides good development opportunity to China financial innovation. But it is also a huge test to Chinese financial theoretical study and innovation. "Grasping opportunity and facing to challenge" would be the basic attitude for us to face to the weather derivatives development.

\section{Help Our Nation Grasp Favorable Status in International Financial Market Competition}

World's economic and financial centers commonly have comparatively developed economic foundation and optimized derivatives market, such as Chicago, London, and Hong Kong, etc. The development of financial derivatives market is good for improving the international competitiveness of financial market. We have made promise when we entered WTO to realize financial field overall 
opening up to the outside world in 2006. Chinese finance would also be involved in international financial market competition. Then how to grasp favorable status in international competition becomes vital. Foreign countries started study on weather derivatives market very early, and have accumulated rich practice experience, which make them standing at the favorable status of competition. Though for us, weather derivatives in financial field is still a new substance, in order to grasp favorable status in international financial market competition, we shall grasp opportunity, positively develop weather derivatives products, accelerate and optimize domestic financial market system, try to enhance international competitiveness of domestic finance, and take full use of late-developing advantages.

\section{APPLICATION PROSPECT OF WEATHER DERIVATIVES IN CHINA}

The Chinese financial market has four conditions: one is that an optimizing supervisory system and law and relative regulation system have been established; two is that the market has got a batch of mature futures types, such as corn, bean pulp, and natural rubber, etc; three is that the personnel team engaging in futures market has been standardized day by day; four is that the futures market is developed stably and its trading volume rises again stably. For the development of Chinese weather derivatives, certain technical conditions are also mature: one is that we have latedevelopment advantages; two is the meteorological data guarantee; three is the infrastructural facility guarantee; four is the professional talents guarantee, etc. Therefore, viewing from technical data, preliminary conditions for us to establish derivatives market have been formed.

On the choosing of weather derivatives development route, we shall promote stage by stage to gradually establish optimized weather derivatives category system according to the principle of "from simple to complicated, from low level to high level, from low risk to high risk". On the choosing of weather derivatives types, we may start from the most fundamental futures, and then promote to trading of option and swap; on the designing of types, we shall take the most mature foreign temperature index product as the guide; and on the market orientation, we shall firstly consider providing service to certain industries. China is a big manufacture and agriculture country. Especially, agricultural population occupies $70 \%$ of the total. So the agriculture has huge demand potential for weather derivatives.

For the development of weather derivatives market, on one hand, the development of weather derivatives is the effective way to promote the enhancement of Chinese productivity and farmer's income; on the other hand, the development of weather derivatives could promote the industries having relation with weather.

\section{REFERENCES}

[1] Brockett P.L, M. Wang, and C. Yang, Credit Risk, Basis Risk, and Weather Hedging [EB/OL], Working Paper, 2003b, University of Texas at Austin
[2] Cao, M., and Wei, J..Weather Derivatives Valuation and Market Price of Weather [J].The Journal of Future Markets, 2004,24(11):1065 1089

[3] Sveca J., and Stevens M., on Modeling and forecasting temperature based weather derivatives [J], Global Finance Journal, 2007, 18 (2):185-204

[4] Banks Weather Risk Management: Markets, Products and Applications [M]. Translated by Li Guohua Beijing: Economic Management Press, 2004

[5] Qi Shaozhou and Ling Ling (Leng) American Weather Derivatives Financial Instrument Model and Application [J] Securities Market Herald, 2003 (11), 25-29

[6] Chen Jing Development and Application of Weather Futures in China [J] Shanghai Finance, 2004, (12):10-13 